\title{
BANALIZAÇÃO DA FRAUDE ACADÊMICA: REFLEXÕES À LUZ DA TEORIA DA SEMICULTURA DE ADORNO*
}

\author{
Carolina Machado Saraiva de Albuquerque Maranhão ${ }^{1}$ \\ Flávia Carolini Pereira dos Santos ${ }^{2}$ \\ Pamella Thais Magalháes Ferreira ${ }^{3}$
}

\begin{abstract}
Resumo: A banalização da fraude no ambiente acadêmico impóe severos problemas à formação dos indivíduos. Este estudo fez uso da teoria crítica relacionada à educação. Adorno analisou o problema da semiformação na sociedade capitalista, em que a educaçáo se tornou mais uma mercadoria a ser entregue a seus consumidores. $\mathrm{O}$ objetivo deste artigo foi propor a reflexão crítica sobre os reais sentidos da persistência da fraude nas universidades. Portanto, a fraude acadêmica destaca-se como uma evidência de que há algo errado com a educação fornecida pelas universidades. Somente uma mudança pedagógica pode transformar o caminho da educaçáo inserida na sociedade capitalista. O resgate do potencial emancipatório da educação é fundamental para que a sociedade possa formar pessoas críticas e autônomas.
\end{abstract}

Palavras-chave: Fraude acadêmica. Semicultura. Adorno. Educação.

\section{TRIVIALIZATION OF ACADEMIC FRAUD: REFLECTIONS IN THE LIGHT OF THE THEORY OF ADORNO'S SEMICULTURE}

\begin{abstract}
The trivialization of fraud in the academic environment imposes severe problems to the training of individuals. This study used the critical theory related to education. Adorno analyzed the erudition problem in the capitalist society, in which education has become a commodity to be delivered to its customers. The aim of this paper is to propose a critical reflection of the real meanings of the persistence of fraud in universities. Therefore, the academic fraud stands as an evidence that something is wrong with the education provided by universities. Only a pedagogical change can transform the way that education is embedded in capitalist society. The rescue of the emancipatory potential of education is essential for society to form critical and self-employed people.
\end{abstract}

Keywords: Academic fraud. Semiculture. Adorno. Education.

\footnotetext{
*Artigo resultado do projeto de pesquisa "PIVIC - 2S/2015 - Banalização da Fraude Acadêmica: Reflexôes à Luz da Teoria da Semicultura de Adorno", financiado pelo PROPP/UFOP.

${ }^{1}$ Universidade Federal de Ouro Preto (UFOP) - Ouro Preto (MG), Brasil.

E-mail: prof@carolmaranhao.com.br

${ }^{2}$ Universidade Federal de Ouro Preto (UFOP) - Ouro Preto (MG), Brasil.

E-mail: flaviapereirasantos2011@hotmail.com

${ }^{3}$ Universidade Federal de Ouro Preto (UFOP) - Ouro Preto (MG), Brasil.

E-mail: pamella.magalhaes0@gmail.com

DOI: $10.1590 / E S 0101-73302016158799$
} 


\title{
LA BANALISATION DE LA FRAUDE ACADÉMIQUE : RÉFLEXIONS À LA LUMIÈRE DE LA THÉORIE DE LA SEMI-CULTURE DE ADORNO
}

\begin{abstract}
RÉSUMÉ: La banalisation de la fraude dans le milieu universitaire impose graves problèmes à la formation des individus. Cette étude a utilisé la théorie critique liée à l'éducation. Adorno a analysé le problème de l'érudition dans la société capitaliste, où l'éducation est devenue une marchandise à livrer à ses clients. Le but de ce papier est de proposer une réflexion critique sur la signification réelle de la persistance de la fraude dans les universités. Par conséquent, la fraude scolaire se tient comme preuve que quelque chose ne va pas bien avec l'enseignement dispensé par les universités. Seul un changement pédagogique peut transformer la façon que l'éducation est intégré dans la société capitaliste. Le sauvetage du potentiel émancipateur de l'éducation est essentiel de façon à ce que la société puisse former les gens critiques et indépendants.
\end{abstract}

Mots-clés : La fraude académique. Semi-culture. Adorno. L'éducation.

\section{Introdução}

A fraude acadêmica é um tema polêmico, dada a sua infestação na prática acadêmica nos últimos anos. Existem vários tipos de atividades fraudulentas: comércio de trabalhos, principalmente na internet, pesquisas on-line, falsificação de frases e parágrafos de autores de livros e cola em avaliaçóes. Apesar de estar presente em debates e constantemente ser pauta jornalística em mídias de grande circulação, como o jornal Estado de Minas e a revista Exame, ainda acredita-se haver necessidade de uma reflexão mais atenta sobre as consequências sérias que a fraude deixa para a educação. Segundo Pimenta (2010, p. 127), "se por um lado há uma percepção de transgressão, de equívoco e de ilegalidade na prática da traição/burla, há também uma glamourização”.

A discussão sobre fraude está presente em vários campos de estudo: filosofia, sociologia e direito. Neste último, por conta do tratamento dado ao sujeito que comete a fraude no âmbito jurídico, é vista como ato ilegal. Ao analisar a fraude se faz necessário refletir além da punição e do tratamento ilegal que se atribui a ela. Pensa-se muito no que fazer depois que a fraude já foi cometida. Há algo muito pior ocorrendo que corrobora a prática fraudulenta: o esvaziamento do sentido da educação em formar sujeitos capazes de uma reflexão crítica. Destarte, a educação fracassa na concretização dos ideais iluministas de libertação da opressão e torna-se alienante. Sem a capacidade de manter uma relação crítica com a realidade, o sujeito desenvolve o sentimento de conformismo, de aprisionamento à realidade factual. 
O objetivo deste artigo foi propor a reflexáo crítica dos reais sentidos da persistência da fraude no ambiente acadêmico. Analisamos aqui a fraude acadêmica como uma representaçáo da incapacidade da escola (aqui entendida no sentido lato: instituição, docentes e discentes) de cumprir seu potencial de emancipação dos sujeitos. A fraude acadêmica é uma expressão da necessidade de pensarmos sobre os reais sentidos dessa prática em nossas atividades pedagógicas. Afinal, quais são as raízes da prática da fraude acadêmica? Qual é o papel dos professores? Como a relaçáo de ensino-aprendizagem, que deveria ser fundamentada no desenvolvimento do conhecimento e da autonomia, pode conter a fraude de forma táo disseminada como temos visto nas salas de aula?

Por meio da reflexão sobre a decadência da cultura e da educação, este estudo buscou seu posicionamento ao discutir que a prática da fraude precisa ser compreendida em sua essência, e não banalizada, restringindo sua análise somente ao campo legal. Se ela existe e é uma prática tão frequente em nossas salas de aula, é porque alguma coisa tem a nos dizer acerca do efetivo sentido da educaçáo. Em um ambiente efetivamente esclarecedor e crítico, acreditamos que a prática da fraude não teria muito espaço, já que ela subtrai dos momentos de aprendizagem a capacidade dos discentes de se tornar profissionais melhores e sujeitos de seu conhecimento. Ao contrário, realizando-se a fraude, acreditamos que esta denota que o produto da educação não é mais aquele ideal de sujeito esclarecido, para se transformar no preenchimento tecnocrático de tarefas vazias de sentido, estabelecidas por um sistema educacional acrítico. Nessa configuração, o trabalho acadêmico torna-se um fetiche: algo para se ter, sem alma, vazio por si só, cuja existência se justifica nele mesmo, como ícone de uma atividade potencialmente emancipatória, mas que perdeu todo o seu sentido crítico.

Para desenvolvermos esta reflexão, usou-se como base o estudo de Adorno (1996). Nesse ensaio, o autor discute a primazia da esfera da semiformação a respeito da formação cultural plena dos sujeitos. Segundo o filósofo, a primazia da esfera instrumental invadiu a escola e determinou-se como sistema dominante formativo. O espaço para o livre pensar, para a compreensão do mundo, foi obliterado da educação. Os alunos passaram a ser objeto de uma sociedade capitalista, que demandava de suas escolas sujeitos ajustados ao processo produtivo, obedientes e alinhados à ideologia dominante. A crítica adorniana à sociedade capitalista, que, mesmo tendo sido escolarizada, permanece alienada, combina perfeitamente com a situação em que a educação desmobilizadora está inserida. Aquele semiculto que aprende um conceito sem questioná-lo é o sujeito que reproduz o produto da indústria cultural. Faz-se necessário desenvolver intolerância à indústria cultural e buscar uma crítica à cultura da semiformação.

A banalização da fraude vem no sentido de trazer à academia uma reflexão ainda não realizada sobre seu sentido enquanto prática presente nas nossas escolas. O que ela nos diz no tocante ao que estamos fazendo em nossas salas de aula, em nossos programas curriculares e em nossos projetos pedagógicos? 


\section{Referencial teórico}

\section{A teoria da semicultura em Adorno}

Para a discussáo sobre a fraude acadêmica, valemo-nos dos escritos da teoria crítica relacionados à educação. Segundo Pucci (2001), tal teoria refere-se "ao pensamento de um grupo de intelectuais marxistas não ortodoxos, alemães, que, a partir dos anos 1920, desenvolveram pesquisas e intervençóes teóricas sobre problemas filosóficos, sociais, culturais, estéticos gerados pelo capitalismo tardio" (PUCCI, 2001, p. 2). Eles formaram a Escola de Frankfurt, cujos pensadores de maior destaque foram Max Horkheimer, Herbert Marcuse, Walter Benjamin e Theodor Adorno. Este último deixou contribuiçóes de grande relevância para este artigo ao expandir a análise marxista do fetichismo da mercadoria à esfera dos fenômenos culturais.

Adorno (1996) analisou problemáticas educacionais. Seu principal texto sobre o tema é o denominado de Teoria da semicultura, publicado em 1959. Nele, o filósofo teoriza a explicação de reprodução de conhecimento sem finalidade e a busca da emancipação do homem. Aquele que se apresenta semiformado culturalmente está salvo da exclusão: quanto mais parecido individualmente, mais dominado se torna no coletivo. Com isso, quanto mais pessoas estiverem envolvidas na cultura de plagiar trabalhos, mais difícil será diagnosticar o conteúdo autêntico. São os indivíduos semicultos que detêm conteúdos em várias fontes, como livros e sites, mas são incapazes de refletir criticamente e de questioná-los.

Adorno discute a massificação do conhecimento. A cultura não pode ser submissa nem igualada a um bem de consumo ou a uma mercadoria supérflua. Trata-se de um estudo concernente à construção e à estruturação da utilização da mercadoria cultural. A semicultura ocorre quando há a materialização dos produtos pela industrialização. Quando Adorno (1996, p. 396) diz "seu espírito é a semicultura, a identificação", ele explica que quem se identifica com o produto é o semiculto, aquele que por inocência absorve o conhecimento já determinado.

Essa legitimação da produção cultural adaptada às massas induz um comportamento regressivo nos indivíduos que têm seu progresso evolutivo como homem racional limitado pelo abatimento da sua capacidade de questionar o produto da indústria cultural. Schulzke (2014) afirma que os indivíduos entendem que há somente uma única maneira como o mundo pode ser arranjado, por isso se constrói a falsa aparência de necessidade. Conforme Fabiano \& Silva (2012, p. 1.072) enfatizam,

para Theodor Adorno e Max Horkheimer, o termo "indústria cultural", por eles criado em 1947, demonstra as apropriaçóes mercantis da produçáo cultural e as suas implicaçóes sociais na atualidade. Veiculada nas diversas instâncias sociais ao pa- 
dronizar estereótipos culturais, a indústria cultural distorce a percepção das contradiçóes da sociedade, ou, ainda, permite perceber as contradiçóes, mas não questioná-las.

Cada livro é reproduzido para atender às classes sociais. Assim, são espalhadas cópias para alimentar os indivíduos que não percebem sua própria alienação. Villela (2007) ressalta com veemência quando Adorno clama em seus textos por justiça curricular, por uma educaçáo que vise à autonomia e a uma sociedade mais justa.

Pucci (2003) afirma que Adorno, ao escrever o ensaio da Teoria da semicultura, "caracteriza descritivamente o duplo caráter da categoria cultura (Bildung), como autonomia do espírito e, ao mesmo tempo, sua conformação com a vida real" (PUCCI, 2003, p. 6). Portanto, a cultura, elemento que teria a capacidade de emancipação, tem seu sentido corrompido para o sujeito, o que é muito pior que a ausência de cultura. Consequentemente, ocorre a sua desconstrução, gerando a semiformação em vez de atingir o potencial de instigar indivíduos verdadeiramente esclarecidos e antenados com a realidade.

Por fim, o filósofo remete que a única forma de resgatar a cultura seria levantar um questionamento crítico sobre o processo de semiformaçáo. A cultura como concebida hoje é somente uma mercadoria que aliena o sujeito, tornando-o impotente de reflexão e envolvido em uma formação danificada pela indústria cultural. De acordo com Adorno (1996), a crítica à educação das massas discute:

O que, na realidade, enfrenta, além do fetichismo da cultura, e ousa chamar-se cultural é só o que se realiza em virtude da integridade da própria figura espiritual e repercute na sociedade mediatamente, passando através de tal integridade e náo por um ajuste imediato a seus preceitos. [...] Contudo, a única possibilidade de sobrevivência que resta à cultura é a autorreflexão crítica sobre a semiformação, em que necessariamente se converteu (ADORNO, 1996, p. 411).

Foi atribuído à cultura um tratamento de mercadoria. Ela perdeu seu sentido, transformou-se em um produto e foi transfigurada em um valor de troca. São vários os instrumentos usados pela indústria cultural para entorpecer os indivíduos e distorcer a realidade: livros, jornais, revistas, meios de comunicação de massa (rádio, televisão, redes sociais), entre outros. Medrano \& Valentim (2001) citam um desses instrumentos:

Um dos instrumentos usados pela Indústria Cultural, de fácil acesso à população, é a televisão. Ela chega à escola, quer através de programas governamentais, quer através de informaçóes veiculadas por professores, alunos, diretores e funcionários. Com isso, cria necessidades que muitas vezes não se tem, por 
meio dos mais diversos recursos visuais, com efeitos especiais e publicidade, com uma linguagem de sedução e convencimento, despertando o desejo de consumo. Reforça estereótipos muitas vezes criticados por todos nós quanto a preconceitos, raças, classes sociais etc. Desta maneira, contribui para deformar a percepçáo da realidade, por meio da reprodução de situaçóes que passam a fazer parte do cotidiano (MEDRANO; VALENTIM, 2001, p. 71).

Outro instrumento utilizado pela indústria cultural:

Além dos meios de comunicação, a Indústria Cultural também invade a escola através de material pedagógico-didático. Sob o pretexto da modernização, tem-se a impressão de que quem não adere a este movimento está trabalhando de maneira retrógrada (MEDRANO; VALENTIM, 2001, p. 72)

A barbárie não conduz a sociedade à emancipação; somente a educação tem essa capacidade. Porém, unido ao capitalismo, esse fenômeno capaz de formar a consciência dos indivíduos torna-se uma arma de dominação e submissão. Só essa consciência esclarecida privaria o homem de repetir os erros do passado, como as atrocidades cometidas ao ser humano e ao seu espírito na época da Segunda Guerra Mundial, a chamada barbárie. Iop (2009, p. 23) articula:

A preocupação de Adorno é impedir o retorno à barbárie, possibilidade que vislumbra apenas na educação. Adorno declara a necessidade de uma formação que proporcione a emancipação da consciência, somente possível por meio da cultura (formação cultural), não pela industrialização da cultura (semicultura), pois esta gera a semiformaçáo, tornando a sociedade dependente das relaçóes de produçáo e sem condições de compreender o processo histórico no qual está inserida. Portanto, forma-se uma sociedade com homens alienados.

Engana-se quem pensa que só o fornecimento de cultura resolveria o impasse da sua formação. A contradição encontrada no legado da indústria cultural é a conformidade do ser humano a essa alienação imposta disfarçada de liberdade. É como se o sujeito soubesse que existe outra escolha, mas optasse pela permanência da dominação das próprias ideias. Por conseguinte, ao mesmo tempo em que se criam novas formas de liberdade, são produzidas novas formas de oprimir os sujeitos.

Para livrar-se dessa opressão, deve-se cobrar a realização das promessas iluministas de liberdade da dominação. "Portanto, uma formação para emancipação requer que o sujeito se reconheça como pertencente e participante do processo cultural produzido pela coletividade" (FABIANO; SILVA, 2012, p. 1.082). 


\section{Fraude acadêmica}

A prática da fraude no ambiente acadêmico é um problema que necessita ser observado com mais atenção. A crise gerada não se restringe somente aos corredores das universidades, mas ao comprometimento do papel da educação. Portanto, as consequências herdadas por essa prática são muito piores que o ato em si.

Souza (2003), ao discutir o gênero fraude no direito tributário brasileiro, enfatiza a sua denominação: "É o vocábulo derivado do latim fraus, fraudis (engano, má-fé, logro), que serve para caracterizar o engano malicioso ou a ação astuciosa, promovida de má-fé, para ocultaçâo da verdade ou fuga ao cumprimento do dever" (SOUZA, 2003, s.p.).

Walker \& Holtfreter (2015) pautam a sua discussão sobre a fraude nas universidades no âmbito jurídico. Para os autores, a prática fraudulenta é considerada um desvio e subdivide-se em desonestidade acadêmica e má conduta de investigação. Já Pithan \& Vidal (2013) se posicionam de forma diferente ao discorrerem acerca da dimensão ética da fraude enquanto plágio. Eles afirmam que essa dimensão antecede a própria questão jurídica do problema, visto que influencia diretamente no próprio ato de se fazer ciência, no que se refere à integridade científica ou à integridade na pesquisa, pois quem comete o plágio "não furta apenas palavras, e sim algo muito mais valioso no consciente coletivo da sociedade que é a confiança na produção científica" (PITHAN; VIDAL, 2013, p. 78).

Nas universidades, a prática fraudulenta também é sinônimo de enganar, burlar e falsificar. Rego (2010, p. 190) argumenta: "A fraude acadêmica deve ser entendida como uma tentativa de burlar os mecanismos de avaliação da produção individual e coletiva".

Existem vários estudos ao redor do mundo que discutem a prática fraudulenta nas faculdades. Na China, segundo Lin (2013), a referida prática é associada a três fatores: falta de punição severa no sistema de avaliação, busca excessiva de lucros pessoais e falta de ética científica. $\mathrm{Na}$ África do Sul, Setleng \& King (2012) apontam por meio de uma pesquisa em uma universidade o nível de consciência dos estudantes que cometem o ato. O estudo mostrou que $41 \%$ dos graduandos pensam que o plágio é muito grave, mas este ainda é praticado. Constatou-se também que $71,9 \%$ dos alunos admitem usar a internet para compilar suas atribuiçóes. Eles também utilizam livros e artigos de revistas como possíveis fontes para o plágio.

Nos debates brasileiros, os tipos de fraude acadêmica recebem várias denominaçóes que constituem a atividade fraudulenta de acordo com cada regiáo. Conforme Pimenta \& Pimenta (2015, p. 127) discutem, 
no Brasil, costumamos nos referir à traiçáo/burla, ou seja, ao comportamento desonesto no meio acadêmico como cola (região sudeste), pesca (região sul), fila (região nordeste). A situação é tão ostensiva que já se percebe manifestaçóes quanto à gravidade desse fenômeno. A reflexão sobre suas consequências vêm sendo tema de livros e estudos e ocupando espaço na mídia.

A fraude acadêmica é cada vez mais noticiada em jornais e revistas de grande circulação no Brasil. Um dos tipos de fraude acadêmica que mais rendem comentários, por ser muito conhecido, é o plágio. Vários escândalos se tornaram públicos, conforme Pithan \& Vidal (2013, p. 77) argumentam:

Em março de 2011, o Ministro da Defesa da Alemanha, KarlTheodor zu Guttenberg, renunciou ao cargo em funçáo de uma denúncia de que ele havia cometido plágio em sua tese de Doutorado, pela Universidade de Bayeuth. Conforme a notícia, o ministro admitiu "graves erros" cometidos em sua tese de Direito, e chegou a pedir à universidade que retirassem o título dele. Ele é acusado de ter copiado passagens inteiras de outras teses sem citar os autores.

Pithan \& Vidal (2013) exemplificam outro caso envolvendo um tipo de fraude acadêmica que obteve grande repercussão na mídia:

Em abril de 2012, outro caso de plágio emblemático também levou ao afastamento do cargo de um político de alto escalão na Europa. O presidente da Hungria, Pál Schmitt, renunciou ao seu cargo de presidente, diante do parlamento de seu país, após acusaçốes de ter plagiado a sua tese de doutorado. Tais acusaçóes levaram ao cancelamento do seu título de doutor, pela Faculdade de Medicina da Universidade Semmelweis de Budapeste, após averiguaçóes das denúncias (PITHAN; VIDAL, 2013, p. 77).

Mesmo com a exposição na mídia, ainda faltam debates mais expressivos. Tem-se a necessidade de trazer a fraude para uma discussáo mais aprofundada nas universidades e pautada na reflexão sobre as consequências graves do enfraquecimento do papel da educação. A fraude acadêmica é uma representação da falta de capacidade da instituição de ensino de efetuar seu potencial de emancipaçáo dos sujeitos. Segundo Pimenta \& Pimenta (2015 p. 217):

Quando vários estudantes consideram que fraudar é uma estratégia a ser divulgada e utilizada, fato observável em vários ambientes, esse fenômeno suscita a necessidade da análise. Além disso, é possível encontrar estudantes e gerentes de empresa que veem a prática da fraude como uma vantagem, ou seja, quem faz demonstra competência para lidar com os obs- 
táculos sem considerar a dimensão ética que ela envolve. [...] mais importante que as implicaçóes apontadas é a grave ameaça à formação ética dos cidadãos e, consequentemente, às bases da civilidade: confiança, justiça e equidade.

Existem vários tipos de fraude acadêmica que se encaixam no conceito entendido por Rego (2010) ao descrever essa prática como uma forma de burlar os mecanismos de avaliação. Com base nisso, serão apresentadas, por diversos autores, as variadas facetas que a fraude assume nas Instituiçóes de Ensino Superior (IES).

Ramos (2012, p. 3) discute o tema:

A fraude acadêmica é uma prática antiga, entretanto, as características da sociedade contemporânea — rapidez, tecnologias digitais e globalização - podem contribuir para sua banalização na atualidade. Entende-se por fraude acadêmica: o plágio, a "cola" e a falsificação de dados de pesquisa.

Sanchez \& Innarelli (2012, p. 46-47) citam várias atitudes fraudulentas:

Nelas estão incluídas várias modalidades, como fraudes em exames escolares (realizadas com ou sem a permissão de colegas), a cópia de ideias alheias sem atribuir créditos ao autor (plágio), colaboração em atividades designadas para serem desenvolvidas de modo individual, fabricar ou falsificar bibliografias, beneficiar-se de trabalhos realizados por outros, etc.

Entre os tipos de fraude na academia, destaca-se também o comércio eletrônico de trabalhos, configurado principalmente em venda e compra de monografias. De acordo com Sauthier, Matheus e Fonseca (2011, p. 51), "há alunos que pagam para que alguns construam e analisem os dados do seu trabalho de conclusão de curso (TCC), pesquisadores que fraudam dados, ajuste de resultados estatísticos, entre outras fraudes citadas".

O plágio praticado pelos discentes é identificado por Ramos \& Pimenta (2013, p, 204) "como a reprodução integral ou parcial de uma obra pertencente a outro sem lhe destinar o crédito em uma produção acadêmica".

Já Sanchez \& Innarelli (2012, p. 48) afirmam: "Mais que a simples cópia de trechos literários, a academia tem reconhecido diferentes tipos de plágio". Os autores destacam a existência de quatro formas de plagiar: autoplágio, autoria fantasma, plágio literário e plágio de conteúdo. A primeira forma dá-se quando o indivíduo recorre a um trabalho próprio já publicado para escrever textos de outra maneira; a segunda beneficia autores que não contribuíram para a redaçáo do trabalho ou ajudaram tâo pouco que sua autoria é irrelevante; a terceira consiste na cópia de frases ou trechos inteiros de livros substituindo as palavras por outras 
parecidas; por último, a quarta forma denomina-se de plágio de conteúdo, em que se utilizam as ideias do autor original sem apresentar as referências devidas.

Outra famosa modalidade de fraude usada em avaliaçóes é a cola. Associada à goma, pela semelhança de aderir aos objetos, a cola talvez seja uma das principais preocupaçóes dos docentes no ambiente escolar. Conforme Barbosa $\&$ Barreira $(2013$, p. 2), essa associação leva a pensar a "cola como uma prática em que o aluno vai aderir ao papel ou prova (sem muito esforço) um material que não resulta de uma efetiva elaboração do trabalho escolar".

A prática da fraude acadêmica em suas diferentes formas se prolonga há anos e atinge um patamar táo grave que fragiliza a possibilidade da educação de transformar sujeitos e emancipá-los. O tratamento dado aos indivíduos fraudadores não deve se restringir somente ao seu julgamento legal. Se esse fato se repete com tanta frequência é porque algo de errado está acontecendo com a formação intelectual, ética e social dos discentes, que podem vir a se tornar docentes no futuro.

\section{A banalização da fraude como uma esfera da semicultura}

Existe uma relação inevitável entre a reprodução do conhecimento sem finalidade e a prática da fraude acadêmica nas IES cometida pelos indivíduos semicultos, incapazes de refletir criticamente sobre os próprios atos não só na academia, mas em sua vida social.

A discussão acerca da banalização da fraude nas universidades traz a reflexão de que há algo muito pior que a prática fraudulenta em si. É preciso analisar tal ato em sua essência. Se essa proliferação da fraude está cada vez mais presente na mídia, ainda falta inseri-la em debates com profundo questionamento crítico. Deve-se eliminar essa ideia errônea de vitimização da escola e preocupar-se com a distorção do sentido da educação. A fraude acadêmica seria um reflexo da semiformação gerada pelo espelho da educação danificada. Os alunos, ao cometerem a fraude, pensam que estão obtendo algumas vantagens. É mais fácil para os estudantes se adaptar a essa realidade, por conta do entendimento deteriorado que eles conferem ao ensino, porém isso só os torna mais alienados.

Ao realizar uma pesquisa concernente a fraudes em avaliaçóes tanto com estudantes quanto com professores, Pimenta (2010) percebe que há uma banalização e glamourização ao cometê-las, visto que elas representam uma "forma de solução dos desafios da vida social e corporativa" (PIMENTA, 2010, p. 124). A fraude é vista como estratégia para lidar com situaçóes indesejáveis. O autor relata ainda que, após a pesquisa de campo e a bibliográfica, há aparência de resultados que indicam a fraude relacionada à honestidade e à confiança, "que alguns professores fecham os olhos e que mesmo em um curso de formação de professores ela é significativamente usada" (PIMENTA, 2010, p. 124). 
Pithan \& Vidal (2013) asseguram que a fraude não deve ser reduzida a soluçôes somente punitivas (sem subestimar sua ilegalidade), mas deve-se considerar também a relação institucional e pedagógica que o problema apresenta. Há a defesa de um trabalho interdisciplinar nas instituiçôes, inserindo práticas pedagógicas que visam à "educação moral" e que sejam alicerçadas na integridade científica.

Assim, o próprio processo pedagógico pode recuperar a formação, além de despertar o espírito crítico para as amarras da dominação, contudo a relutância de que existe o "diferente" pode ser uma barreira para esse alcance. A sociedade acostumou-se a ser padronizada, a pensar e a agir da mesma maneira, a conviver apenas com a mesma cultura e até a cometer os mesmos erros. Enquanto a universidade tiver a função de formar mão de obra para abastecer o sistema capitalista, o progresso da educação ficará petrificado.

A fraude seria o objeto usado pelos discentes para reproduzir o conhecimento sem absorvê-lo como fonte de emancipação, da mesma forma que o produto da indústria cultural é o objeto da semicultura. A cultura discutida por Iop (2009) leva os indivíduos à formação cultural e, consequentemente, à emancipação por meio da aproximaçáo e da descoberta das obras de arte. De acordo com o conceito abordado pela autora, a cultura tem como característica ser "toda ação humana sobre o contexto natural e social e o resultado dessa ação, configurando-se em fenômenos sociais, políticos, econômicos, religiosos, artísticos, bem como na expressão de um conjunto de valores, sendo possível sua representação pela obra de arte" (IOP, 2009, p. 21). Portanto, se a educação é repassada às gerações pela cultura de modo danificado, não estamos mais nos referindo à cultura, mas sim à semicultura. Então, sob o risco de repetir os erros do passado pela sociedade do presente, "a única possibilidade de sobrevivência que resta à cultura é a autorreflexão crítica sobre a semiformação, em que necessariamente se converteu" (ADORNO, 1996, p. 410).

A educação pode reaver o projeto de esclarecimento. A emancipação surge do resgate desse projeto. Quando o indivíduo reconhece seu lugar no mundo, torna-se autônomo de suas açóes, protagonista da sua própria história, oposto ao conformismo, capaz de correr riscos e fazer diferente dos demais. Reformulando tal constatação para o ambiente acadêmico, quando o estudante, sujeito autônomo, compreende o potencial da educação, passa a ser apto a desconfiar do produto da indústria cultural. Além disso, ao se tornar autocrítico, o discente verá a fraude na universidade de outro modo, fazendo com que sua prática seja desnecessária.

\section{Considerações finais}

O artigo dedicou-se ao estudo da educação crítica visando a uma formação menos alienante e à capacitação de sujeitos conscientes do papel da educação. Isso impediria a passagem repetida de conhecimento de forma mecanizada e desmotivadora de futuros professores para alunos. Além disso, a teoria da 
semicultura (ADORNO, 1996) possibilitou o debate educacional com foco político-social. A fraude seria uma representação da semiformação imposta, pois, ao estabelecer um sistema massificado, se gerou um entendimento danificado da educação. Então, o que é educação? Não seria esse o momento ideal para refletirmos sobre o porquê da existência da fraude e sua permanência no ambiente acadêmico? Quais as motivaçôes dos indivíduos envolvidos nessa prática?

É passível de consideração, após refletirmos diante do exposto, que a semiformação se assenta na educação concebida como produto. O ideal iluminista de emancipação dos sujeitos e de um sistema educacional que visa à construção crítica e ao esclarecimento do indivíduo é suprimido por uma educação que objetiva formar profissionais orientados para contribuir com o mercado capitalista. Assim, ocorrem a semicultura e a semiformação, pelo fato de a cultura e a educação terem se tornado um produto da industrialização.

Valbuena \& Belalcázar (2014) discutem que cada IES deve ter compromissos éticos claramente formulados que permitam definir o papel da instituição e de cada um dos seus membros conforme a rede de informação em um contexto de pluralismo, igualdade, respeito, honestidade, solidariedade, justiça e liberdade. A universidade deve abordar as causas dos variados tipos de fraude, e não apenas reagir aos seus efeitos. Por outro lado, vê-se cada vez mais que a pretensão dos discentes e docentes, com toda a carga absorvida na graduação, é de que sejam alcançados um aprendizado e um conhecimento aceito pelo mercado industrial.

Por conseguinte, a educação transformou-se num produto adquirido pelos alunos, como forma de garantir a eles a qualidade de servir também como um produto ao mercado industrial. A banalização que se chegou por conta da fraude advém da educação como produto, ou seja, da semiformação, pois há despreocupação por parte dos educadores e alunos em desvelar os sentidos ocultos da realidade, o que seria capaz de transformar o discente em um ser crítico e justo. Assim, a fraude é encoberta pelo sistema educacional acrítico, pois ela acredita estar apenas seguindo uma espécie de protocolo em suas exigências acadêmicas, tornando o trabalho acadêmico um preenchimento tecnocrático com tarefas sem sentido, justificadas em si e vazias. A fraude é banalizada, já que se apresenta como a aparência do aprendizado; trata-se da expressão máxima da fetichização da educação, reificada e reduzida a produtos, e expressa na entrega de bens educacionais (trabalhos acadêmicos), cumprindo-se com a exigência burocrática de atendimento às necessidades do sistema educacional estabelecido. As necessidades, repetimos, são do sistema, e não dos sujeitos que o compóem, configurando uma educação esvaziada de sentido formativo.

Soroya, Hashmi e Soroya (2014) afirmam que, na sociedade em geral, e particularmente na paquistanesa, os alunos tendem a idealizar, consciente ou inconscientemente, seus professores. A atitude pessoal e profissional dos docentes e seu comportamento com os alunos podem afetar o crescimento pessoal e acadêmico 
discente. Portanto, os conteúdos ministrados pelos docentes nas instituiçóes de ensino por meio de métodos que visam somente à reprodução geram nos alunos um comportamento reflexo de também corresponderem com a reprodução - consolidação da semiformação - e com o acréscimo. Ainda, a falta de políticas pedagógicas que visam ao esclarecimento e à punição da desonestidade acadêmica acaba por dar características de permissividade e banalização à fraude. Ou seja, a banalização da fraude consolida-se, mais uma vez, como um produto da semiformação.

Diante do que nos foi exposto, podemos afirmar também que a fraude não advém somente da prática e da banalização pelos discentes, docentes e instituiçôes como a semiformação. Ela está presente no próprio significado de educação, na semiformaçáo. Se a fraude está relacionada ao ato de burlar algo, a partir do momento em que a educação passou a ser praticada como uma produção industrial — que garante a ela a característica de semiformação — para suprir as necessidades do sistema capitalista, garantindo o caráter acrítico na formação, agindo com a condescendência de todos os envolvidos no processo de formação e educação — banalização — , podemos perceber que a fraude não é apenas um produto externo desses fatores, mas sim se inicia na própria corrupção dos significados de educação e formação, uma vez que nem a educação nem a formação objetivam mais a emancipação dos sujeitos. Assim, a educação transfigurada em semiformação já é uma fraude, e não há como reproduzir consequências distintas a ela. Banalizou-se a educação, banalizou-se a fraude.

Conquanto, acredita-se em uma mudança pedagógica no tocante aos fatores que envolvem e determinam a fraude. Crê-se, ainda, na erradicação da prática educacional como uma mercadoria que tem como propósito a formação de mão de obra para contribuir com o sistema capitalista. Esse modelo, ao ser substituído por um espaço de atuação acadêmica construída pelo pensamento dos próprios discentes, levará ao despontamento de indivíduos com pensamento transformador, consolidando um novo objetivo: formar seres críticos, questionadores e éticos, em detrimento de uma formaçáo que alimente uma sociedade que reproduza os erros comuns. Ordorika \& Lloyd (2014) discutem que as universidades foram aprisionadas pela globalização em conflitos de um cenário político que transforma o conhecimento em acumulação de capital. Logo, restringem o potencial de emancipaçáo dos sujeitos pertencentes a essas IES. O resgate do potencial emancipatório da educação é fundamental para que a sociedade possa formar pessoas críticas e autônomas. Com isso, a fraude tornar-se-ia uma prática desnecessária e sua disseminação seria minimizada.

A pretensão com esta reflexão foi lançar luz à questão da fraude acadêmica sob o enfoque do seu significado enquanto prática presente em nossas salas de aula. Pensamos que ela é um indicador do sentido da educação na sociedade capitalista. Somente o resgaste do papel da educação pode promover ao indivíduo a capacidade de reconhecer seu lugar no mundo como sujeito esclarecido e crítico em sua formação. 


\section{Referências}

ADORNO, T. Teoria da semicultura. Educação e Sociedade, Campinas, ano XVII, n. 56, p. 388-411, 1996.

BARBOSA, J.A.C.; BARREIRA, C.M.F. As práticas de cola na universidade e sua relação com os processos de ensino, aprendizagem e avaliação. 2013. Disponível em: <http:// docplayer.com.br/9064425-As-praticas-de-cola-na-universidade-e-sua-relacao-com-osprocessos-de-ensino-aprendizagem-e-avaliacao-.html>. Acesso em: 3 ago. 2015.

FABIANO, L.H.; SILVA, F.A. Massificação cultural, práticas educativas e autonomia social. Diálogo Educacional, Curitiba, v. 12, n. 37, p. 1065-1084, 2012.

IOP, E. Formação cultural, Semicultura e indústria cultural: contribuições de Adorno sobre a emancipação. Espaço Pedagógico, v. 16, n. 2, p. 20-33, 2009.LIN, S. Why serious academic fraud occurs in China. Learned Publishing, v. 26, n. 1, p. 24-27, 2013.

MEDRANO, E.M.O.; VALENTIM, L.M.S. A indústria cultural invade a escola brasileira. Cadernos Cedes, ano XXI, n. 54, p. 69-74, 2001.

ORDORIKA, I.; LLOYD, M. Teorías críticas del Estado y la disputa por la educación superior en la era de la globalización. Perfiles Educativos, v. 36, n. 145, p. 122-139, 2014.

PIMENTA, M.A.A. Fraude em avaliaçóes na visão de professores e de estudantes: uma reflexão sobre formação profissional e ética. Profissão Docente, Uberaba, v. 10, n. 22, p. 124-138, 2010. Disponível em: <http://www.revistas.uniube.br/index.php/rpd/article/ view/187/579>. Acesso em: 16 out. 2015.

PIMENTA, M.A.A.; PIMENTA, S.A. Fraude acadêmica: estudo comparativo entre o Nordeste e o Sudeste do Brasil. Revista Série-Estudos, n. 39, p. p. 213-230, 2015.

PITHAN, L.H.; VIDAL, T.R.A. O plágio acadêmico como um problema ético, jurídico e pedagógico. Direito \& Justiça, v. 39, n. 1, p. 77-82, 2013.

PUCCI, B. Indústria cultural e educação. In: VAIDERGORN, J.; BERTONI, L.M. (Org.). Indústria cultural e educação: ensaios, pesquisas, formação. Araraquara: JM, 2003. p. 9-29.

Teoria crítica e educação: contribuiçóes da teoria crítica para a formação do professor. Espaço Pedagógico, v. 8, p. 13-30, 2001.

RAMOS, F.S. Fraude acadêmica: uma análise ético-legislativa. Dissertação (Mestrado em Educação)-Universidade de Uberaba, Uberaba, 2012. Disponível em: <http://www. uniube.br/biblioteca/novo/base/teses/BU000279533.pdf>. Acesso em: 3 ago. 2015.

RAMOS, F.S.; PIMENTA, M.A. Plágio, propriedade intelectual e produção acadêmica: uma discussão necessária. Revista Eletrônica do Curso de Direito da UFSM, v. 8, n. 2, p. 204-218, 2013.

REGO, S. Índice H, autoria e integridade na produção científica. Revista Brasileira de Educação Médica, v. 34, n. 2, p. 189-190, 2010.

SANCHEZ, O.P.; INNARELLI, P.B. Desonestidade acadêmica, plágio e ética. GVexecutivo, v. 11, n. 1, p. 46-49, 2012. 
SAUTHIER, M.A.F.A.J.; MATHEUS, M.P.; FONSECA, P.M.L.D. Fraude e plágio em pesquisa e na ciência: motivos e repercussōes. Revista de Enfermagem Referência, v. 3, n. 3, p. 47-55, 2011.

SCHULZKE, M. The virtual culture industry: work and play in virtual worlds. The Information Society, v. 30, n. 1, p. 20-30, 2014.

SENTLENG, M.P.; KING, L. Plagiarism among undergraduate students in the Faculty of Applied Science at a South African Higher Education Institution. South African Journal of Libraries \& Information Science, v. 78, n. 1, p. 57-67, 2012.

SOROYA, M.S.; HASHMI, M.A.; SOROYA, S.H. Student-teacher relationship and its impact on academic integrity: a case of university of the Punjab. Pakistan Library \& Information Science Journal, v. 45, n. 2, p. 41-48, 2014.

SOUZA, E.C.F.A Fraude à lei no direito tributário brasileiro. Checkpoint, 2003. Disponível em: <http://www.fiscosoft.com.br/a/2d26/a-fraude-a-lei-no-direito-tributariobrasileiroedino-cezar-franzio-de-souza $>$. Acesso em: 23 jul. 2015.

VALBUENA, S.J.; BELALCÁZAR, N.R. Los estudiantes universitarios y la sociedade de la información: una combinación que há facilitado el plagio académico em las aulas comlobianas. Informacion, Cultura y Sociedad, v. 30, p. 127-137, 2014.

VILLELA, R.A.T. Críticas e possibilidades da educação e da escola na contemporaneidade: liçóes de Theodor Adorno para o currículo. Educaçâo em Revista, n. 45, p. 223-248, 2007.

WALKER, N.; HOLTFRETER, K. Applying criminological theory to academic fraud. Journal of Financial Crime, v. 22, n. 1, p. 48-62, 2015.

Recebido em 20 de janeiro de 2016.

Aprovado em 26 de julho de 2016. 